\title{
The Constitution of Risk Communication in Advanced Liberal Societies
}

Publication details:

Wardman, J. K. (2008) The Constitution of Risk Communication in Advanced Liberal

Societies, Risk Analysis, 28(6): 1619-37

The definitive version is available at:

http://www3.interscience.wiley.com/journal/121410145/abstract

Author details:

Jamie K. Wardman

School of Psychology

Faculty of Health, Life and Social Sciences

University of Lincoln

Brayford Pool

Lincoln, LN67TS

Email: jwardman@lincoln.ac.uk

\section{Acknowledgements}

The author is grateful to Ragnar Lofstedt and David Demeritt for comments on an earlier draft of this article. 


\begin{abstract}
This article aims to bring to the fore some of the underlying rationales that inform common conceptions of the constitution of risk communication in academic and policy communities. 'Normative', 'instrumental' and 'substantive' imperatives typically employed in the utilisation of risk communication are first outlined. In light of these considerations a theoretical scheme is subsequently devised leading to the articulation of four fundamental 'idealised' models of risk communication termed the 'risk message' model, the 'risk dialogue' model, the 'risk field' model and the 'risk government' model respectively. It is contended that the diverse conceptual foundations underlying the orientation of each model suggest a further need for a more contextualised view of risk communication that takes account not only of the strengths and limitations of different formulations and functions of risk communication, but also the underlying knowledge/power dynamics that underlie its constitution. In particular it is hoped that the reflexive theoretical understanding presented here will help to bring some much needed conceptual clarity to academic and policy discourses about the use and utility of risk communication in advanced liberal societies.
\end{abstract}

Key words: Risk communication; governmentality; field/habitus; dialogue; sender/receiver 


\section{Introduction}

Risk communication has become increasingly prevalent as an area of academic research, with one recent review accounting for 349 risk communication articles published within the environmental and technological risk fields alone between 1988 and 2000 (Gurabardhi et al 2004; Gurabardhi 2005). A literature search recently conducted on behalf of the UK Government Inter-Departmental Liason Group on Risk Assessment (ILGRA 2002) claimed to have revealed over 1000 English language publications on risk communication in the 10 years prior to the review, providing further indication that the risk communication field is clearly a vast and rapidly growing area. Whilst some academics have attempted to trace some qualitative aspects of the development of risk communication over the past thirty years or so pointing to how best practice has evolved for example (for useful reviews see: Fischhoff 1995; Gurabardhi et al 2004; Gurabardhi 2005; Krimpsky date; Leiss 1996; Lofstedt 2005; National Research Council 1989; McComas 2006; Palenchar and Heath 2007), others have also noted the systematic embedding of risk communication in regulation and corporate governance (see for example: Gouldson et al. 2007; Hood et al. 2001; Lofstedt 2005; Power 2004; Rothstein et al. 2006). The quantitative expansion of formalised interest in risk communication is particularly made apparent by the broad distribution of national and international agencies that have increasingly documented and advised on the requirement for risk communication, as well as its role within their own organisations and for others (see for example: European Food Safety Authority 2006; ILGRA 2002; ISO 2002; OECD 2002; UK Government Cabinet Office Strategy Unit 2002; US National Research Council 1989; World Health Organisation 2002). However, despite the apparent evolution and popularisation of formal approaches to risk communication opinion can be said to be divided over its purpose and suitability. On the one hand it would seem that many academics, public health practitioners, industry consultants and policymakers amongst others variously find intrinsic appeal to the notion of risk communication and see ever broadening possibilities for its potential application. For example, an influential report for the US National Research Council (1989) identified that growth in government interest in risk communication has been driven by such diverse motivations as the requirement and desire to inform, to overcome opposition to decisions, to share power, and to seek alternatives to direct regulatory control. In turn, the day-to-day provision of risk communication would appear to be seen by many advocates as encompassing a wide variety of modes and formats, which on the face of it are to a varying degree seemingly facilitative of meeting these objective concerns.

On the other hand, the application of risk communication has also faced strong criticism that it may be adopted quite restrictively and as such be easily dismissed as amounting to no more than simply a form of 'PR' or 'spin'. According to Jasanoff (cited in Morgan and Lave 1990) many officials seem to regard risk communication as a codeword for 'brainwashing' for example. Nelkin (2002) has likewise observed that risk communicators have frequently presented exaggerated claims about the pros of adopting new technology verses the negative consequences of failing to do so as a strategic ploy to help resolve risk conflicts. Nelkin also further notes that in such disputes public and stakeholder concerns can often become reduced to technical questions to be answered by recourse to 'better' science alone; if any residual fears still remain it is through information conveyed via risk communication that a resolution is to be found. Risk communication has therefore arguably been marked by its utilisation for perpetuating beliefs that new technologies are unequivocally beneficial rather than for more noble goals such as 
encouraging the public debate about their possible adoption and use. Pidgeon and Rogers-Hayden (2007) have similarly questioned whether traditional forms of risk communication have evolved sufficiently to accommodate broader social values, implications and visions for the future that have been emphasised in recent trends towards 'upstream engagement' about new technologies.

In light of these criticisms it does seem reasonable to question how far the rhetoric and ideas of risk communication actually translate into socially valued communicative action or whether indeed they were ever intended to do so. But furthermore, even when risk communication has been implemented in good faith and according to plan, it seems that the possibility for 'effective' risk communication is far from certain and that in some instances it may in fact do more harm than good (Fischhoff 1995; Lofstedt 2005). These reservations about the 'reality' of risk communication in practice therefore raise fundamental questions about the very purpose of risk communication and how its use and utility might, in principle, be conceived. Yet, seemingly few attempts have been made to try to distil different academic and policy conceptualisations of risk communication and to integrate this knowledge in a coherent fashion. One notable problem, as McComas (2006) observes, is that whilst research on risk communication is diverse and multidisciplinary in nature, and thus draws from a well-rounded pool of knowledge and expertise, the field suffers from few integrative theoretical frameworks which makes it difficult to centralise or to capitalise on this knowledge (see also Bostrom and Lofstedt 2003; Lofstedt and 6 2008). Indeed, parsing the academic literatures across different disciplines it is not always made altogether clear how different theories and practices of risk communication are connected. Furthermore, whether in relation to science, health, politics, lifestyle, technology, or the environment, despite being ostensibly united by a shared language, different communities with a common interest in risk communication typically seem to talk past one another, perhaps being divided by their own particular outlooks, understandings and experiences (Horlick-Jones 2008).

All this has perhaps exacerbated the problem that the underlying beliefs commonly concerning the conceptualisation of risk communication processes and their outcomes are rarely acknowledged or subjected to proper rigour and scrutiny. Hence, as with much risk communication research, a growing number of often instructive reviews have instead generally maintained an atheoretical focus, with reviewers and researchers for the most part intent on highlighting the most important challenges facing the increasing number of agencies and organisations that suddenly find they have a risk communication problem. This has in turn led to the prescription of 'best practice' solutions to help address those particular risk communication problems. But, as has been similarly observed of other fields by Richardson (1996), the adoption of such 'toolbox' approaches arguably permits risk communicators, analysts and policymakers to 'draw from a wide body of techniques without necessarily being aware that the techniques they adopt bear the imprints of broader scientific, political, economic or social theory [or that] ...they are permeated by power/knowledge relations' (p289). Consequently, the prevailing atheoretical understanding of the application of risk communication lends itself to confusion or the possible imposition of particular value frames which mask the effects of power and distort risk management and regulatory policy processes.

Against this critical backdrop the remainder of this article addresses the apparent theoretical lacuna concerning the constitution of risk communication as advocated and practiced in advanced liberal societies. I begin by first briefly outlining 'normative', 'instrumental' and 'substantive' 
imperatives for engaging in risk communication, as reflected for example in calls for greater public engagement in risk appraisal and decision making more generally (see Fiorino 1990; Stern and Fineberg 1996; Pidgeon 1998; Pidgeon and Rogers-Hayden 2007; Rowe and Frewer 2000; Stirling 2005). It is suggested that the practical orientation of risk communication around these imperatives is connected to more or less implicit assumptions not only of the purpose or function of risk communication, but also about how that purpose or function will be brought into effect. However, these assumptions are rarely fully articulated in terms of existing social and psychological theories of communication. What follows is a critical exposition of how the constitution of risk communication may be theorised in light of these objective concerns. By demarcating different interpretations of risk communication within an integrative theoretical account it is hoped that this will help to bring some conceptual clarity to academic and policy debates and empirical inquiry concerning common understandings, intentions, impacts and practices of risk communication.

\section{Three imperatives for risk communication[1]}

First characterised by Fiorino $(1989 ; 1990)$, the 'normative' imperative for risk communication as it is adopted here stems from a process-based ethic which typically considers that risk communication is undertaken simply because it is 'the right thing to do' without particular reference to the ends or outcomes to which it may lead (see also Pidgeon and Rodgers-Hayden 2007). This view is guided by the belief that as there is a value dimension to risk, and citizens are the best judge and executers of their own interests, risk communication should raise people's awareness of risk and enable citizens to be party to individual risk decisions that personally affect them and their communities (see Fiorino 1990; Pidgeon and Rogers-Hayden 2007; Stirling 2005). However, to the extent that risk communication is thought to be a valued end in and of itself the normative imperative can actually be seen to be informed by two democratic ideals. The first ideal centres on the obligation by actors, such as individuals, groups, business organisations or government agencies, in liberal democracies of Western politics to inform (Powell 2000). Operating on this basis risk communication may be orientated towards fulfilling such functions as the 'public right-to-know', 'freedom of information', 'informed consent' or 'emergency preparedness' through the disclosure of information about the risks of hazards to potential victims as well as behavioural advice and guidelines prior to or during acute risk situations and emergencies. The second ideal entails the view that citizens should be involved in risk communication allowing equal opportunity for representation and participation in debates about how risk is characterised and managed for example. Recent risk communication research has indicated and largely supported a general trend towards facilitating stakeholder involvement in deliberative dialogue to help characterise risk and set risk management priorities and policies which represent a cross-section of interests (Klinke and Renn 2002; Lofstedt 2005; Petts 2001; Stern and Fineberg 1996). From the normative perspective risk communication can therefore be seen as fulfilling two valued roles that are thought to represent the interests of the individual citizens of a society, but whereas the first implies risk communication is a process of experts speaking out to the public, the second implies the process of various publics speaking back to experts.

In contrast to the normative imperative, the instrumental imperative construes risk communication as a resource or means that may be employed by an individual, group or organisation to help them 
achieve the particular ends they seek. In this context risk communication has often been conceived essentially as a corporate survival mechanism that evolved in strategic adaptation to the external pressures placed on industry following such incidents as Bhopal (Chess 2001) and Chernobyl (Wynne 1989; 1992), the BSE or 'mad cow' crisis (Leiss 1996) and conflict over the dumping of the Brent Spar oil storage platform in the North Sea (Lofstedt and Renn 1997). The value of risk communication is therefore understood instrumentally in these respects according to how it might support the particular aims of an organisation faced with a potentially hostile environment in which different actors vie to realise their own interests and ambitions. From this point of view an organisation is often specified as the communicator in a 'battle for the hearts and minds' of target audiences such as citizens or government in light of counter claims-making activities by other stakeholders and the media for example (Gouldson et al. 2007). An organisation's commercial interests may therefore dictate that risk communication is utilised in a wish to smooth the path of a potentially controversial new product to market by co-opting stakeholders into decisions, or by assuaging public concerns in the face of criticism from NGOs, the media or other interested parties. For such uses the organisation in question is no doubt attributed to be the most direct beneficiary of risk communication, and it is largely from within this frame that risk communication has been admonished for helping organisations to reach instrumental objectives particularly if it is at the expense of others. However, in so much as risk communication can be conceived as an instrumental resource it can quite clearly be deployed by host of different individuals, groups and organisations for a variety of particular ends. The success of organisations like Greenpeace International in raising awareness and amplifying the controversy that has surrounded the disposal of Brent Spa, global warming or the commercial development of genetically modified food crops and other such campaigns is a testament to this fact (see for example Bakir 2005).

Finally, the substantive imperative advocates that risk communication should be utilised to generate improvements in understanding and the quality of knowledge available when making risk related decisions. Proponents of this position contend that it may be possible to generate better decision outcomes by generating insights from a variety of sources with different points of view that might not otherwise have been accounted for via a purely technocratic or individualistic approach (e.g. Wynne 1989). The substantive argument therefore often goes hand-in-hand with the deliberative ideals identified above and reflects a concern that risk communication may play a crucial role in attempting to close critical gaps between what is known by different actors about a particular risk in question and what needs to be known. The substantive argument may however also become aligned with instrumental concerns, but in contrast to purely instrumental concerns the substantive imperative for risk communication is conventionally portrayed as motivated by the wish to achieve outcomes that favour the general interest rather than self-serving ends (Stirling 2005). One stated goal of organisational risk communication preferred by some academics in these respects is to help people in society to make health risk choices wisely either through education or the advocacy of certain behaviours in citizens (Bostrom 2003). This may occur when trying to help people put new risk information into perspective both for themselves and for others so as to improve their understanding and the quality of risk decisions for example (see Ropeik and Slovic 2006).

The nuances of the substantive position also come sharply into focus in view of the use of risk communication for the resolution of risk conflicts. For example, Fischhoff (1995) has advocated 
that one objective of organisational risk communication is to facilitate a focus within society on 'fewer, but better' risk conflicts that include the consideration of both social concerns as well as scientific principles (see also Renn 1998). The implication here is that risk communication can serve the general good by providing a means not only for parties to focus their attention and resources on what matters most, but also in helping them to figure out what matters most. From a substantive point of view the purpose of risk communication in these respects is the establishment of understanding, not necessarily conflict resolution. As Krauss and Morsella (2000) contend given a genuine desire to resolve conflict good communication may help people to achieve that aim through facilitating better understanding, but it cannot guarantee that conflict will be resolved or even ameliorated. Even when people caught up in conflict understand the situation at hand as well as the perspectives, intentions and motivations of one another there may still be legitimate fundamental reasons for disagreement. But where as in the words of Mahatma Ghandi 'honest disagreement is often a good sign of progress', poor communication can lead to misunderstanding, which may instead increase the likelihood that conflict will be exacerbated or misplaced (Krauss and Morsella 2000).

\section{Theorising risk communication}

The normative, instrumental and substantive imperatives outlined above indicate that risk communication can be conceived as fulfilling a wide variety of objective purposes. However, to date there has been relatively little discussion of how these imperatives may overlap or come into conflict with one another, or about the implicit assumptions of communicative action held within each of these imperatives. Indeed, what is not fully articulated thus far is a functional understanding of how communication actually 'works' and how this understanding can inform different conceptualisations of risk communication, its research or its practice. The theoretical approach that has arguably come closest to achieving such an endeavour is the Social Amplification of Risk Framework (SARF) developed and introduced by Kasperson et al. (1988). This conceptual framework is generally well noted for providing a general understanding of the role of risk communication in connecting risk events and their economic, social and psychological outcomes. However, the idea here is not to develop a unified theory or conceptual framework of risk communication, but to outline a theoretically driven conceptual scaffold which may in turn help to inform present understandings of risk communication in different respects. In light of the different imperatives outlined above, and particularly if, as Horlick-Jones (2008) has recently argued, responses to risk are not intrinsically instrumentally calculative, but reflect the specificity of the risk issue in question and of the settings in which it is encountered, it therefore also seems reasonable to concede that no single generic view of risk communication will suffice. Rather the conceptualisation of risk communication might perhaps benefit from adopting a similarly contextualised and differentiated approach.

The theoretical approach presented is thus organised around a conceptual scheme which identifies four idealised 'models' of risk communication (see Figure 1). These models are conceived in light of the normative, instrumental and substantive imperatives for engaging in risk communication outlined above and allow for perspectives drawn from contemporary communication theory. The vertical axis of Figure 1 conveys the implied communicative intent or driver of risk communication (i.e. normative or instrumental), whereas the horizontal axis characterises the coinvolvement of different agents in the social construction of risk (i.e. how potential participants 
are seen to be substantively engaged in constituting communicative action and risk meaning). It is suggested that the fundamental orientations of these perspectives along these two axes can therefore be seen to characterise the constitution of risk communication represented by each of the four associated risk communication 'models'. These risk communication models are developed with particular reference to the work of Krauss and Fussel (1996) whom have specified different perspectives of inter-personal communication within social psychology, as well as the seminal work of social theorists such as Foucault, Habermas, Bourdieu and Luhmann. As 'ideal types' each of the four models depicts risk communication as constituted in a distinct form that may in principle help to guide communicative action in a particular context, but which will never be fully realised in practice. Instead, it is contended that these models offer complementary insights into specific aspects of risk communication theory and practices which serve to illuminate the inherent strengths and weaknesses of different approaches, and so each should not be considered in isolation. The conceptual foundations underlying each model are presently discussed in turn.

\section{[pic]}

\section{Figure 1. Four conceptual models of risk communication.}

\section{The 'risk message' model}

Following the normative imperative to inform, the 'risk message' model of risk communication as it is termed here is predicated on the underlying assumption that the environment in which risk communication takes place can be compared to a 'free market' system in which goods are produced, transported, purchased and consumed. In this environment risk messages are subjected to a 'market test' whereby well produced, accessible messages will find their market niche if the receiver can process them with little disruption or distraction, but poorly produced risk messages will eventually fail (Jaeger et al. 2001). A central concern of the risk message model is that risk communication should accord with a concern for transparency. Transparency has long been held as a key component to modern democracy and public service reform more generally and has recently been upheld as an antidote to problems of distrust by helping to prevent secrecy in organisations and by promoting public accountability (Hood and Heald 2006). However, in so far

as risk communication fulfils goals such as being transparent and informative the primary objective of transferring risk messages is the reduction of uncertainty. That is to say, according to this conceptualisation risk communication can be specified in quantitative terms as the free conveyance of informational content in risk messages to add or enhance knowledge about risk and risk-related knowledge. The task for risk communicators is therefore to ensure that an efficient uninterrupted flow of clear, concise and comprehensible risk information from sender to receiver (as well as any subsequent feedback) is obtained (see also Fischhoff 2005a). This perspective is reflected in commonly used definitions by academics and policy makers that regard risk communication in a general sense as:

"The flow of information and risk evaluations back and forth between academic experts, regulatory practitioners, interest groups, and the general public" (Leiss 1996, p. 86).

Or as stated by the National Research Council (1989, p. 21): 
"an interactive exchange of information and opinion among individuals, groups and institutions. It involves multiple messages about the nature of risk and other messages, not strictly about risk, that express concerns, opinions or reactions to risk messages or to legal and institutional arrangements for risk management".

The constitution of risk communication according to the risk message model has its roots most closely in the 'encoder/decoder' communication paradigm (otherwise known as the 'sender/receiver' or 'transmission' model after Shannon and Weaver 1949)[2]. Following Krauss and Fussell (1996) in the encoder/decoder paradigm 'meaning' is said to reside as a property of messages. That is to say, the meanings of messages are fully specified by their elements, whereby meaning is encoded in the message and that decoding the message is equivalent to specifying its meaning. Following the encoder/decoder paradigm in risk communication, risk information, or meaning, is transferred via a process in which an abstract risk proposition (i.e. mental model or belief about risk) is:

a) encoded in a risk message (i.e. transformed into a signal whose elements are seen to have a one-to-one correspondence with the elements of the proposition) by the sender;

b) transmitted as a signal over a channel to a receiver;

c) decoded by the receiver into an abstract risk proposition which, it is believed, is in principle isomorphic with the original one;

d) utilised by the receiver as a means by which to reduce uncertainty and guide action.

The receiver may in response to the message act or send their own message and these responses might then be collected by the original sender as feedback. Senders and receivers are generally conceived to produce, process and respond to risk messages in accordance with the 'rational actor paradigm' (Jaeger et al. 2001), but the recipients of messages are as such substantively disengaged from contributing to the generation of the meaning of risk messages. If the message decoded by the receiver is found not to be identical to that transmitted by the sender this is thought to be because: the size of the signal relative to 'noise' (i.e. signal-to-noise ratio) during message transmission is not great enough; the message was incorrectly or insufficiently encoded by the sender; or finally, that the message was incorrectly decoded by the receiver.

To briefly elaborate on these last three points following Krauss and Fussel (1996): First, in the encoder/decoder paradigm it is assumed that there are often many messages in transmission at any one time, and that messages are not always transmitted directly between senders and receivers, but may be relayed by intermediaries, or 'transmission stations' to use SARF terminology (see Kasperson et al. 1988). All communication can therefore conceivably contribute some degree of 'noise' to a message which increases the likelihood that a message may become distorted or perhaps even rendered incomprehensible during transmission (Krauss and Fussell 1996). For example, individuals make use of multiple sources of risk information in their day-to-day lives, or information is often mediated by other sources such as the mass media or other individuals they may come into contact with (Alazewski and Horlick-Jones 2002; Wardman 2006). The noise generated by the prevalence of other messages, as well as the mediation of risk messages by other sources can therefore adversely affect the signal-to-noise ratio. This then requires message recipients to fill in missing information that any noise has omitted or distorted and may lead to the increased likelihood of misunderstanding. The greater the signal there is relative to noise, then the 
closer the transmitted message will be to the original message, and hence the more similar the received proposition is likely to be to the original one limiting the opportunity for misunderstanding (Krauss and Fussell 1996). Second, information may be encoded incorrectly or insufficiently when the sender omits essential details in the linguistic representation of meaning contained within messages that are necessary to construct the correct mental representation of that meaning. In such cases receivers may necessarily have to fill in missing detail from pre-existing knowledge and experience. Finally, even when linguistic representations are received in their entirety, incorrect decoding may still arise because the mental representations of the receiver may inevitably differ in some respects to those of the sender, which might not be recognised from the outset. This variance could be due to different understandings of terms used in linguistic expressions and representations, or the misapplication of those terms when they are reconstructed into mental representations by the receiver (Krauss and Fussell 1996).

This communication paradigm serves as a powerful heuristic in risk communication, as Jaeger et al. (2001) have observed it is the one most utilised in communication studies and employed by risk managers. Indeed, the encoder/decoder paradigm is central to the SARF (Kasperson et al. 1988), which is arguably one of the most prominent theoretical frameworks informing the risk communication field at this time. Perhaps to a lesser extent the encoder/decoder paradigm also figures in the 'mental models approach' (Morgan et al.2002), which centres on fashioning and correcting the provision and design of risk message content in line with the knowledge of the respective parties concerned[3]. Yet, despite the apparent appeal of the encoder/decoder paradigm, and by extension the risk message model, a number of criticisms can be made of its dominant position in the common conceptualisation of risk communication. For example, in instances where distortion is likely to occur Krauss and Fussell (1996) have observed that 'redundancy' (i.e. the multiple and repeated encoding of messages) is the communication strategy accordingly considered to increase the likelihood that messages will be correctly understood (see also Krauss and Morsella 2000). However, this shows the risk message model to be somewhat simplistic in its conception. One notable problem when communicating risk is that encoding and decoding can both be further hampered by the complexity of the risk concept (Jaeger et al. 2001). For example, transparency is often advocated as a means by which to reduce uncertainty by increasing information available to public scrutiny, but according to O'Neill (2002) transparency in the form of the full disclosure of information might actually result in information overload for recipients and generate further uncertainty. Furthermore, in many instances there is in fact often an abundance of information about risk especially in the news media, but people still tend not to pay any attention (Renn 2006). In which case, it might be argued that simply providing more information does not in itself necessarily lead to greater understanding because people not only need the means or capacity by which to be able to judge new information, they must also have the motivation to do so.

A further concern is that following the conventional wisdom of the risk message model risk communication has at times unfortunately been construed mechanistically and asymmetrically as a 'one-way' form of communication from sender to receiver. This is typically interpreted as meaning communication from 'expert' officials within organisations to 'lay' members of the public. In one-way communication the lay public are considered to be deficient in their knowledge about a particular risk issue and that this has to be remedied through disseminating information or publicising official viewpoints derived from experts (Fischhoff 1995). But unless those 
institutions responsible for sorting and assessing information are trusted then there is little reason to suppose that more information (as through greater transparency) is going to lead to the acceptance or adoption of a particular risk proposition (see O'Neil 2002). Even when organisations are required to be transparent it may be in the reasonable interests of outside observers to withhold their trust, or to deploy 'critical trust' in those sources concerned (Walls et al 2004). Risk communication failure according to the 'deficit model' as it has come to be known is instead conceived as a disruption or breakdown in the transmission of risk messages from authorities or the miscoding of that information by its recipients. Moreover, whenever there is public doubt or scepticism about the risk information being transmitted this is typically attributed to ignorance, scientific illiteracy, or irrationality, which can in turn then be used as justification for excluding others from making a substantive contribution to risk debates (Sturgis \& Allum 2004; Wynne 1989; Wynne 1991). However, as these scholars and others such as Fischhoff (2005b) and Leiss (1996) forewarn one-way communication can generate the impression that recipients are being managed, learning no more than an authority wants them to know, and as such these actions can result in alienating the intended recipients of communications.

Clearly in the face of such concerns the provision of more information through mechanisms such as redundancy and transparency is plainly not a panacea for the problem of uncertainty in risk communication. While the risk message model assumes that recipients form judgements solely on the basis of the message, the fact that people are embedded in complex social networks and relations which influence expectations, commitments and understandings is generally overlooked or ignored (Jaeger et al. 2001; Horlick-Jones 2008). One attempt to elaborate on the broader social dynamics inherent to risk communication is the SARF first proposed by Kasperson et al. (1988) and later elaborated upon by these and other authors (see Pidgeon et al. 2003 for example). In the SARF the 'amplification' metaphor refers to the intensifying or attenuating of risk signals during the transmission of information from an information source to transmitters and finally to a receiver. Each transmitter may alter the original message by adding or deleting incoming signals and sending a new cluster of signals on to the next transmitter or receiver. The SARF in particular usefully elaborates on the societal context of risk message exchanges by indicating that risk events are mediated by the interplay of physical, individual and socio-cultural variables. This broader emphasis therefore highlights the potential direct and indirect impacts of risk communication on other actors, groups, and organisations such as the stigmatising of technologies and public health treatments, or economic losses and wider regulatory impacts.

In certain respects however, the amplification metaphor utilised by the SARF is a limited representation of the social dynamics that are present during risk communication (see Rayner 1988). According to the SARF approach risk messages may be imbued with signal value which is amplified by transmission stations at various stages, but it retains the central premise of the encoder/decoder paradigm that meaning resides as a property of the risk message that is being transmitted. A communicative exchange is therefore still conceived to amount to little more than the combined outputs of autonomous information processors. So although the proponents of the SARF try to emphasise the wider social interactions and impacts arising from risk events, and also notably declare an interest in moving critical attention away from one-way communication to the potential for two-way communication, relatively little consideration is generally given towards elaborating in any great detail upon the social dynamics and influences that may also feature in the co-construction of risk meaning (see also Murdock et al. 2003). 
These general shortcomings to the risk message model are arguably because the complex social processes that may be of interest often do not form part of the message, but are inherent to the 'noise' that is conceived as the lesser part of communication to be avoided or filtered out. Risk communication researchers and practitioners therefore usually try to uncover or amplify the 'true' risk signals contained within messages and to facilitate direct correspondence of risk meaning between communicating parties. Contrary to this view however, fields such as discourse psychology and anthropology have highlighted that by focussing upon noise and variability in the context of their occurrence one might in fact find a different kind of order and coherence that reveals specific rhetorical uses and functionalities of communication tailored to particular contingencies and instances of interaction (Edwards 2005). For instance, Boholm (2008) contends that the pragmatics of risk communication demand that in addition to content and the manner of presenting that content, complex social processes of meaning creation and interpretation situated in real life also need to be taken into account. As of yet, and despite its relative advances the SARF approach has not explicitly incorporated a consideration of pragmatics, or indeed the importance of 'noise' more generally, into its development and conceptualisation of risk communication. The three remaining risk communication models that are subsequently presented expand upon different ways in which the social basis for risk communication may be understood, and therefore provide a useful counterpoint to the basic tenets of risk message model.

\section{The 'risk dialogue' model}

The second concern of the normative imperative for risk communication highlighted above is for the participation of citizens and other stakeholders in risk related debate and decision making. Recent risk communication research has, for example, indicated and largely supported a general trend towards facilitating stakeholder involvement in deliberative dialogue to help characterise risk and set risk management priorities and policies which represent a cross-section of interests (see Stern and Fineberg 1996; Lofstedt 2005). In line with this view, the 'risk dialogue' model as it is termed here considers risk communication as an historically situated discursive engagement between all those who become involved in a particular risk issue. In risk dialogue actors are regarded equally and treated like partners allowing them greater responsibility to shape how risks are managed and share what is learned about them to make a substantive contribution to risk debates (see Fischhoff 2005b). As with concepts of deliberative democracy no particular viewpoint is excluded a priori and the interests of everyone are considered.

In contrast to the risk message model a distinctive feature of the risk dialogue model lies in the notion of two-way risk communication as a collaborative interaction. Participants in risk dialogue not only have to be responsive to how others engage with them in communication, they also need to be responsive to other stakeholders whom might have different information needs and perspectives or insights to offer. A communicative exchange is conceived not as the combined outputs of two or more autonomous information processors, but as a fluid joint accomplishment of participants whom have collaborated to achieve substantive understanding together (see Krauss and Fussell 1996). That is to say, risk dialogue does not consist of a set of discursively related independent episodes through which speakers act with respect to one another individualistically, but is an intrinsically social and cooperative activity whereby meaning creation is situated in particular discursive context. Whereas in the risk message model it is assumed that people communicate to convey information which may be used by others to enhance their understanding 
about risk for example, in the risk dialogue model although information exchange is part of the communication process, risk understanding is achieved through inter-subjectivity. In this sense, mutual understanding is not something that is thought can be achieved purely through the exchange of knowledge about the world, but is fashioned anew out of the divergent social realities which participants bring together (Jovchelovitch 2007). According to Krauss and Fussell (1996) such inter-subjectivity is also continually modified by acts of communication, and what is made known by what is said is affected by what is tacitly taken for granted. But because intersubjectivity is assumed to be neither implicit in the knowledge participants bring to the situation, nor explicitly coded in language, for risk communication to be successful participants are obliged to take some pains to ensure that they have a shared conception of the meaning of each utterance before proceeding to the next (see Krauss and Fussell 1996).

According to this model an inter-subjective understanding of risk and thus risk communication is discernable in a Habermasian sense like other communication as a fundamental democratic process which can provide a solution to social risk conflicts by allowing consensus between responsible citizens to prevail through communicative rationality and reasoning (see Habermas 1984; 1987). This does, however, require that a number of ideal speech conditions and 'rational discourse ethics' are met for successful communication to take place. For example, if participants are deemed to be acting intelligibly, truthfully, trustworthily and legitimately then dialogue is assumed to function well (Burkart 2007). But if these ideals are violated, as they often are, then participants become involved in discourse where they have the opportunity to express doubt and interrogate the truth of assertions, the trustworthiness of expressions, or the legitimacy of different interests; only when plausible answers are given will the flow of communication continue (see Burkart 2007). Whether with regard to moral statements or statements of fact, a central component to the risk dialogue model is that the resolution of risk conflict rests upon the possibility for agreement on the most convincing argument or risk-related proposition. To draw on Habermas this is because through deliberative dialogue arguments can be weighed and compared, problems are dissected, better solutions may be negotiated and substantive understanding thus replaces instrumental success as a goal of communication (Pellizzoni 2001). However, as Burkart (2007) observes, substantive understanding is not normally taken as an end in itself, but pursued with the intent of putting interests into reality and allows for the co-ordination of actions and the synchronising of goals on the basis of common definitions of a situation and consensus. Drawing on the 'post-normal science' framework devised by Functowitz and Ravetz (1992), Rosa (1998) has noted for example that the modern world has generated a set of risk problems demanding scientific understanding, but which are quite often too complex or ambiguous to yield to science alone and so must be opened to wider scrutiny and debate by extended peer communities (see also Klinke and Renn 2002). For Rosa (1998), the key question to be addressed is 'how we [can] best use our various systems of knowledge to improve our democratic decision making over risk choices?' (p40).

The conventional wisdom here is seemingly that the higher the decision stakes and the more uncertainty and social ambiguity that are associated with a risk problem, then the greater the need for risk dialogue. This deliberative ideal therefore offers not just a theoretical perspective of how risk communication might take place, but reflects a normative imperative for what could in principle be achieved by consenting parties. Yet, contrary to popular opinion and despite recent trends, engaging people in dialogue about risk though often important and essential to the policy- 
making process is not problem free and so should not be regarded as the 'be-all and end-all' of risk communication (Lofstedt 2005; Fischhoff 1995). Critics such as Coglianese (1997) and Rossi (1997) have argued that approaches which emphasise participation, dialogue, deliberation and consensus have in practice generally failed to live up to expectations. One notable problem is that the procedures required to match deliberative ideals can be extremely difficult to implement by being both costly and overly demanding on participants. It has also been demonstrated to be difficult to secure a broadly representative selection of participants and ensure that certain parties do not exert undue influence over proceedings and substantive outcomes. Campbell and Townsend (2003) have argued for example that popular opinions about the commercial application of biotechnology in the UK are more ambivalent than was recently represented in the findings of the GMNation? debate (an unprecedented public consultation exercise) one reason being that people who were less concerned were it seems less likely to take part in such a debate (but see Pidgeon et al. 2004).

Risk dialogue can therefore sometimes become narrowly skewed by the sectional interests of selfselecting individuals or groups with their own particular biases or political agendas, but this criticism could at least in principle be addressed procedurally. The risk dialogue model is however beset by two further issues. First, as Pellizzoni (2001) contends, sometimes conflicts are intrinsically deep-lying, principles and factual descriptions profoundly different and uncertainty so radical that no universal reason or best argument may be found. Faced with such difficulties risk controversies can remain intractable no matter what procedures are put in place. Second, authors such as Flyvbjerg and Richardson (2002) have argued that reliance on procedural approaches to communication theory in the Habermasian mould may in fact hamper understanding of the processes of democratic social change by neglecting how power shapes discourse in areas such as environmental planning. In short these critics highlight that a focus on Habermasian ideals of 'what should be done' has unduly limited the appreciation of real world practices in terms of 'what is actually done' and the instrumental dynamics which shape them. These instrumental dynamics and the means by which they act through and upon risk communication provide the focus of the remaining two risk communication models.

\section{The 'risk field' model}

The instrumental imperative outlined above emphasises that risk communication may be understood in light of the strategic conduct of competing social actors and how they distinguish themselves, their intentions and their beliefs amongst those of other actors wishing to further their own particular interests. The orientation of risk communication in these respects can be seen in definitions which for example refer to risk communication as:

"any purposeful exchange of information about health or environmental risks between interested parties" (Covello et al. 1986).

'Purpose' in the above sense is typically seen to be required to distinguish the sending of risk information from noise present during communication and implies an intention to expose the target audience to a system of meaningful signals which may in turn change people's perception of the issue or their image of particular actors (Jaeger et al. 2001). The authors of the SARF have 
suggested for example that symbols attached to message sponsors such as 'big business' or 'NGO' may be included in the transmission of risk messages and can carry strong value implications that can both trigger the attention of potential receivers as well as influence how messages are evaluated (see Kasperson et al. 1988). That other actors involved in risk communication are considered during communication is an important point, but the SARF arguably under specifies how context also provides additional cues for parties to generate interest, draw inferences and interpret other actors' intentions over and above the content of messages. A further concern is that the SARF generally assumes that the actors involved in risk communication are interacting on a 'level playing field', whereas in fact the resources at each actor's disposal are more often distributed unequally or valued quite differently (Murdock et al. 2003). In short, the SARF generally fails to make an adequate account of the importance of context and power in determining the availability of opportunities of different actors to influence substantive risk outcomes.

By contrast, the 'risk field' model as it is termed here is conceived following the work of Bourdieu (1977; 1986) and considers risk communication as occurring within a 'field of activity' wherein the position and social influence of each actor is seen in relation to one another and reflects the various types and amounts of 'capital' (e.g. money, knowledge, connections, prestige) at their disposal (see Murdock et al. 2003; Schedler et al. 1998). The field of activity may relate to such varied concerns as the siting of a nuclear waste repository, the introduction of a new technology or the vaccination of a population against infectious disease for example. Following Bourdieu's (1977) concept of 'habitus', although the strategic conduct of actors within a field is not fixed, their dispositions are historically situated, acquired through socialisation and embedded in accumulated everyday practice and understandings of the 'rules of the game'. An actor's practical sense of how risk communication operates through complex interacting systems of beliefs is thus likely to play a role in influencing the strategy they adopt and ultimately its effectiveness. The field of activity is also considered to be interactive and recursively negotiated in nature. For instance the distribution of capital is an expression of power relationships, which in turn are expressed in rhetorical strategies, which in turn may reshape power relationships. Hence risk communication competence can be viewed as a rhetorical resource, or a form of capital (see Murdock et al. 2003), that is affected by the distribution of other capital, but which can in return also be instrumentally deployed to affect the distribution of that capital. That is, the actions that are generated by the dispositions of different actors are constitutive of the objective conditions and social positioning of actors within a field of activity (Schinkel 2007).

Legitimacy and trust are primary considerations of the risk field model because these qualities help to define the boundaries for decisions and actions that are perceived as acceptable and permitted within a given time and context, and when questioned can increase uncertainty and impact on an organisation's resources (Chess 2001; Holmstrom 2005). A growing body of risk communication literature has indicated that without legitimacy and trust the potential efficacy of risk communication activities can be markedly undermined (see Lofstedt 2005; Cvetkovich and Lofstedt 1999; Slovic 1993). Yet at the same time risk communication has been increasingly advocated as fulfilling a vital role in helping administering authorities to reduce social risk conflicts by securing legitimacy and enhancing trust in risk management and regulation (Pidgeon and Hayden-Rogers 2007). The power of risk communication as represented in the risk field model signifies the strategic play of actors within the possible field of activity, and its expression 
can take many forms such as moral advice, ideological manipulation or rational argumentation. To the extent that the risk communicator's intentions are understood and accepted as legitimate in a particular context risk communication may therefore be considered to be successful. However, as Krauss and Fussell (1996) observe following Grice (1957; 1969) and Austin (1962), communication can be considered successful only in this sense if the interlocutor or 'speaker' intended the communicative exchange to create an effect such as a particular belief in the addressee, and the interlocutor intended that effect to result from the addressee's recognition of that intention. The inherent difficulty which follows is that in order to have a desired impact risk communication must be enacted in such a way as to try to take account of how entire systems of beliefs will respond, though the risk communicator does not know the full content of what is constituted by what they do, or if what they target will be responsive to fundamental change.

Whilst from an instrumental perspective it may be recognised that another actor's concerns sometimes have to be addressed in order to meet particular ends, unlike in risk dialogue there is much less inclination amongst actors to discuss what those ends should be, or to come to a mutual understanding about them, without a forceful incentive. The accomplishment of shared acceptance of a particular risk proposition may as such be primarily attempted by processes of coercion and social influence rather than through being fashioned out of mutual cooperation or consensual intersubjectivity. The robustness of fundamental beliefs and the recourse of actors to instrumental rationalities during communication do however both present a serious challenge to instrumental communication. In broader theoretical terms this challenge may be understood as a consequence of the evolution of present day communication systems or subcultures and their internal dynamics along particular paths. For instance, in Luhmann's (1995) 'systems theory' it is hypothesised that the increasing complexity of society in modernity has led to functional differentiation, that is the clustering of specialised rationales in functional communication systems which each constitutes a particular social reality and whose complexity isolates the system against other communicative realities. These systems are continuously recursively reproduced and changed, but usually only through iterative self-referential communicative processes that select meaning related to previous beliefs and rules. Successfully shifting one belief in an individuated, or subcultural system will not necessarily bring about a desired outcome because other core elements of the system may act to dampen the fundamental impact of any movement or change (see also Breakwell 2001 with reference to Moscovici's 'social representations theory').

This has in turn led to the concern expressed by Boholm (2008) that the possibility for coordinated selection taking place between different actors in risk disputes is particularly low. Risk is a relational, comparative and temporal concept that is commonly subject to different interpretations from diverse standpoints; however, as Boholm further contends the diversity of these standpoints is often differentiated by the agency and sovereignty of those parties involved. For instance, one actor may make decisions according to a particular risk rationale with another being exposed to the consequences of those decisions. Otherwise stated many risk conflicts may not rest so much on debating risk estimates, but the fairness and equity of the technical options presented (Rayner and Cantor 1987). In contexts where the risk dialogue model prevails such power is diffused by actors allowing all parties equal agency in determining risk characterisation and options for its social distribution or mitigation. But in many circumstances different positions may be so entrenched that each actor is reluctant to empower the other party with the sovereignty to make decisions over the issues of most concern to them in such a way which might contradict 
their own subjective understanding and rationale for action. If, or when, different actors reach an impasse over a particular risk proposition, activity or intention, this places even further emphasis on achieving greater legitimacy for one's own perspective in the broad interplay of intentions mobilised by different actors in social risk discourses so that agency might be attained or preserved. Without high levels of confidence and trust, the relinquishing of agency from one actor to another may as such represent a core barrier to the possibility for inter-subjectivity.

Consequently, the social representations of risk that emerge are generally purposeful and shaped by the social polemic that takes place between different actors with the intention of furthering selfserving interests (Breakwell 2001). In this way the context of risk communication as represented by the risk field model thus delimits the possibility for a unified conception of risk, its characterisation and consequences, or what might be done whilst at the same time seemingly increasing the perceived need for risk communication to take place. For instance the risk field model suggests that the requirement for overt risk communication efforts by each actor will likely increase by virtue of the pragmatic value of risk communication in response to the social and political pressures faced when dealing with risk and how they bear upon the agency of each actor concerned. Rothstein et al. (2006) have indicated for example that the implementation of formal risk communication initiatives may be understood in practical terms as a systemic consequence of private and public organisations needing to address the potential 'institutional risks' that inherently arise from attending to 'societal risk' management. An issue often at stake here is that when organisations are officially charged with the responsibility for managing societal risks (i.e. risks to the environment or public health for example) problems inevitably arise which put a spotlight on the limits of institutional arrangements for addressing those problems and can threaten the legitimate functioning of the organisation concerned. Instrumental mechanisms are therefore needed to preserve the integrity and procedural legitimacy of official decisions and regulatory outcomes. Risk communication decisions may thus become shaped by instrumental rationalities to preserve the agency of the organisation in question as much as by any normative concerns or incidences of risk that would have otherwise guided official actions (Power 2004).

In seeing risk communication as fundamentally shaped by powerful discourses, each with its own substantive content as well as internal and external power/knowledge dynamics, we may also consider how social, economic or political forces help to shape and define a particular risk problem and bias risk communication towards certain practices and substantive outcomes. However, it does not necessarily follow that the instrumental use of risk communication is intrinsically 'bad'. The success of many public health risk initiatives for instance may depend upon an organisation's ability to marshal risk communication resources to promote an agenda that does not necessarily work against the interests of those immediately affected even though it may not be totally appreciated or accepted at the time. Although risk communication may be utilised as a way of publicly rationalising particular viewpoints and decisions, the power of risk communication in this sense may also work through appeals to instrumental and calculative rationalities of individuals in ways that do not limit the options available to them in obvious ways, but which enhance their capacity for self-control. That these discursive forces are not often consciously or reflexively accessible to practical risk reasoning on a day-to-day basis, but may nevertheless steer the way people think and feel about risk is considered more fully in the final risk communication model presented in this article. 


\section{The 'risk government' model}

Reconceptualising risk communication as a political enterprise allows for the possibility that rather than being based on communicative rationality, risk propositions may be appropriated as 'truth' through the exercise of power. In this sense the risk field model conceives of power as something held and wielded by one group over another, but whilst the risk field model predominantly focuses on how each actor attempts to utilise risk communication to achieve, maintain or resist sovereignty within a field of activity, the foremost concern of the 'risk government' model as it is termed here is in interrogating how the rules that govern the field of possible activity are structured and bear upon the dispositions and behaviour of those concerned. The orientation of the risk government model is made with particular reference to the concept of 'governmentality' which was first introduced by Foucault (1991) as a way to draw attention to a certain way of thinking and acting embodied in attempts to know and govern the wealth, health and happiness of populations (Dean 1999; Rose 1999; Rose and Miller 1992). In contrast to the risk field model this perspective emphasises unintended consequences and the diffuse nature of power effects that shape actors and their own sense of self and self interest. As a starting point Foucault departs from conventional state-based models of political rule and asserts that the government of a population is contemporarily achieved not via the delegated exercise of sovereign power, but 'through the wide dispersal of technologies of power which are relatively invisible and which function in discursive sites and practices throughout the social fabric' (Smith 2000 p283). For Foucault power relations do not always result in a removal of liberty or options available to individuals, but may empower citizens so that they may actively engage in free choices and decision-making (Rose 1999). In these regards the notion of governmentality suggests how forms of political rule and exploitation are linked to the individual's capacity for self-control and considers how freedom, rather than being the opposite of government is one of its key inventions and most significant resources (see Rose 1999).

In contrast to conventional approaches to risk communication, from a governmentality perspective the prevalence of attention to 'risk' is, following Rose (1999), not seen so much as a consequence of changes in the contemporary existential condition of humans and their world, but as a particular style of thinking which is employed to render the future knowable and calculable. Risk as articulated through governmentality is therefore similar in conception to an aspect of risk associated with Beck's (1992) 'risk society' thesis. According to Giddens (1999) the idea of a 'risk society' does not necessarily imply an increase of risk within society, but rather that society is increasingly preoccupied with the future and safety, which generates the notion of risk and the subsequent organisation of society with regard to this notion. According to Rose (1999) risk thinking forms an individualising logic which facilitates the disciplining of populations by requiring citizens to take upon themselves the responsibility for the security of their persons and their property. For example, for Rose (1999) the multiplication of perceptions of risk through media reporting works to incite a continuous self-scrutiny and monitoring of diet and lifestyle in terms of the avoidance of threats to health but with especial regard to the individual's capacity for self-control. By mobilising perceptions of risk the dispositions and behaviour of individual citizens may, at least in principle, be regulated at distance and the responsibility for maintaining the health of a population is thus transferred from direct state control to the individual.

In risk communication terms the operation of these concerns may be seen in part to parallel 
Sunstein and Thaler's (2003) notion of 'libertarian paternalism', by which it is thought desirable for private and public institutions to influence the behaviour of others if this encourages and respects their freedom of choice. For example, Sunstein and Thaler (2003) have argued that it is not only necessary, but in practice also inevitable that authorities attempt to steer people's choices in welfare promoting directions that would otherwise be restricted by the bounded rationalities and bounded self-control of individual actors. In line with such concerns, Fischoff (2005a) has similarly suggested that as individuals do not follow 'decision theory', so psychological work may find an applied focus by identifying and explaining disparities between normative ideals and the descriptive reality and then aid in the design of prescriptive interventions to help people make 'better' (i.e. more normative) choices. Risk communication interventions may encourage better choices by acting upon people through education or upon their environment through better disclosures as an alternative to curtailing freedom of choice through dissuading people from certain actions or banning particular products (Fischhoff 2005a).

In a Foucaultian sense, libertarian paternalism and the work of psychology as appropriated through risk communication may be seen to represent attempts by authorities to problematise the dispositions and behaviours of citizens in terms of the way in which they ought to maximise their health, wealth and happiness. For example, nutrient labels on food products are designed to 'empower' consumers and consumer choice. Whereas this form of risk communication might be conceived in the risk message model as a conventional top-down strategy to increase information and reduce uncertainty for consumers when choosing a particular food product, a governmentality perspective would indicate how its effects exceed such imperatives and are in fact part of more widespread and diffuse governmental 'programmes of the self'. Otherwise stated, and to paraphrase Rose (1999), the power of risk communication is conceived in these terms not so much a matter of imposing constraints upon citizens as a way of 'making up' citizens capable of bearing a kind of regulated freedom and responsibility determined and acted upon through risk thinking. The process of 'making up' or 'responsibilising' citizens in the risk government model of risk communication is conceived to operate following Rose and Miller's (1992) articulation of governmentality as an expression of 'political rationalities' and 'governmental technologies'. Political rationalities primarily concern the changing discursive and cultural fields within which the exercise of power is conceptualised and the particular ways in which the exercising of power by diverse authorities is morally justified. Governmental technologies concern 'the complex of mundane programmes, calculations, techniques, apparatuses, documents and procedures through which authorities seek to embody and give effect to [political rationalities and] governmental ambitions' ( $p 175$ ). In this light risk communication must be defined both in terms of how and why 'risk' comes to be employed in particular political rationalities and embodied in the governmental technologies (e.g. communication practices such as food labelling) which give effect to those political risk rationalities.

By linking political risk rationalities to governmental technologies it is possible to formulate a conception of risk communication that 'connects the lives of individuals, groups and organisations to the aspirations of authorities in advanced liberal [societies]' (Rose and Miller p176). The orientation of analysis in these respects draws attention to the productive processes and organisational constellations through which risk communication, as with other instruments or 'technologies of government', generates new risk objects, new forms of risk knowledge, subjective identities, dispositions and conduct. By taking a Foucauldian perspective the focus of 
concern in the risk government model thus extends beyond linguistically reflected power exchanges between persons and groups to the discursive and cultural structures within which they are deployed, that is to that which influences the conduct of risk communication conduct. This analytical approach might therefore concern questions such as 'how, given the infinite potential for meaning production in social discourse, do notions of risk come to delimit what it is possible to think and say at a particular time, what purpose does this serve, and to who's benefit?'. For example, past critics have been all too aware that the privileging of risk knowledge and expertise was and often still is seen as essential to the success of risk communication (see for example Wynne 1992). Technical skills such as forecasting, surveying and statistical modelling may in many cases act as influential imagery with which to help persuade audiences of the integrity of risk propositions whilst at the same time limiting the scope of non-experts to define what counts as truth or knowledge.

The privileging of risk related knowledge and expertise can also be seen to work in other ways. For instance, ever more sophisticated testing methods and investigations employed in the social science of risk perception have made available a growing body of knowledge on the structure and function of people's responses to risk. Risk perception research has as such been utilised by decision makers as a tool to support prediction, prevention and remediation through risk communication interventions and programmes in a diverse array of areas. However, it is already evident that the application and evaluation of risk perception research findings has had farreaching effects and implications which perhaps go beyond the original goals of risk perception researchers themselves. Whereas previous scholarly work has revealed that people's dispositions and behaviours in relation to risk are often highly gendered, social, emotive and symbolic, and that theory and methods appropriate to such qualities need to be invoked to produce a valid social science of people's responses to risk (see Joffe 2003), it seems that the prescriptive lessons often drawn from descriptive explanations of individuals' 'gender' and 'emotional', 'cultural' and 'political' dispositions are sometimes used to marginalise particular contributions to risk debate and decision making (see Wardman 2006). That is to say, the construction of subjective dispositions attributed to individuals along such dualistic notions as 'rational/irrational' and 'objective/subjective' embodied in notions of 'gender', 'emotion', 'culture' and 'politics' bear direct relation to validity claims concerning the correspondence between risk perception, risk assessment and 'real' risk and thus their place within the boundaries of legitimate risk debate and decision making. By contrast scientists tend to be considered 'rational' and 'objective' and these attributes render their contributions as having more value in terms of competition for legitimacy and attention on risk related issues (Garvin 2001).

Furthermore, risk perception knowledge also plays an important role in signifying the need for risk communication interventions to facilitate the correction and adjustment of people's dispositions and behaviours. As such the real socio-political impact of risk perception research may be observed not so much in the advancement of risk perception knowledge, but rather the promotion of a form of behavioural determinism in which 'risk perception' serves as a heuristic for all kinds of social and individual divergence from normative ideals[4]. The social power of risk perception knowledge as appropriated by risk communicators may therefore appear to lie less in explaining that which influences the disposition and behaviour of people when at risk, and more in the discursive construction of risk arising from the dispositions and behaviour of populations. That is to say, risk perception would thus be considered here not so much an empirical matter of 
fact, but rather as an invention, or social representation, whose reality rests as the result of a particular form of problematisation concerning the government of people within a population. Seen in this light 'risk perception' discourse serves as a regime of truth that constructs individuals as particular kinds of subjects (Lemke 2004). A Foucauldian approach however steers the prospective analyst away from such sterile dualisms as 'rational/irrational' and 'objective/subjective' implicit to the respective correspondence of different forms of representing risk (such as science or lay experience) and the actual risk reality towards an interrogation of how qualities of knowledge and truth are bestowed upon risk propositions and statements as embodied in risk communication practices (see also Demeritt 2001; Richardson 1996). For example, as articulated through the lens of governmentality the case may be stated that the assessment, predictive testing and appraisal of risk perception can in the above sense be conceived as part of broader socio-political priorities for the management and government of populations observed in a multiplicity of areas of the risk society. The subjective qualities that demarcate risk perception may in themselves thus be regarded as representing a risk to governmental programmes and projects to enhance the health, wealth and happiness of populations which need to be addressed. Fischhoff (1990) has made the telling observation that psychologists, as experts in risk perception, often seem most needed by policymakers when a particular aspect of the public's behaviour threatens their policies. Fischhoff (1990) therefore forewarns that in such cases social scientists, and by extension social science, can quite feasibly be put to work against the public interest on occasions when:

- Political aspersions which cast the public as troublesome are simply and uncritically accepted by academics, thus undermining the public's political credibility.

- Social scientific remedies prescribed to deal with such behaviour shift the political balance against the public interest.

- Claiming to know how to explain their behaviour reduces the perceived need to let publics speak for themselves.

- Assisting policymakers leads to the fortification of their power, by helping them fine-tune programmes, anticipate and overcome resistance, or guide and legitimise initiatives.

- Claiming to know what particular publics might want and need without seeking their clarification is used to justify current actions.

- Research findings are misappropriated by policy makers to justify decisions which actually disadvantage and disenfranchise the people concerned

With this in mind it is interesting to consider that, as indicated earlier, a growing body of literature has generally focussed on the importance of public trust in the success of risk communication.

Yet, by contrast, the risk government model by highlighting governmental forms of power, techniques of surveillance and the regulation of populations instead rather emphasises the question of 'institutionalised mistrust' of the public in the way that populations are constructed in 'at-risk discourses', that is 'at risk of jeopardising through present dispositions and behaviours, desired future [outcomes]' (Kelly 2001 p30; see also Kelly 2003). The ways in which such rationales are embodied in risk communication practices does however deserve much more research attention, but these points serve to illustrate some of the novel ways in which taking a governmentality perspective may contribute to longstanding debates within the risk communication field and highlights possible areas for future academic inquiry. 


\section{Conclusions}

This article seeks to bring to the fore some of the underlying rationales that inform common conceptions of the constitution of risk communication in academic and policy communities. Three imperatives typically employed in the utilisation of risk communication are outlined and a theoretical scheme is subsequently devised to help articulate four fundamental 'idealised' models of risk communication in light of these considerations. It is contended that the diverse conceptual foundations underlying the orientation of each model suggest a further need for a more contextualised view of risk communication that takes account not only of the strengths and limitations of different formulations of risk communication, but also the underlying knowledge/power dynamics that underlie its constitution. In keeping with calls for more integrated approaches to the study of risk within the social sciences (Horlick-Jones and Sime 2004; Taylor-Gooby and Zinn 2006) this article may be seen as not only taking advantage of a cross-fertilisation of ideas from a variety of different disciplines, but also for having highlighted an opportunity for the development of future risk communication research along the many themes identified above. In particular it is hoped that the integrative theoretical understanding presented here will help to bring some much needed clarity to academic and policy discourses about the use and utility risk communication in advanced liberal societies. It is also hoped that it will help to broaden the concept of communication and the scope of empirical inquiry that has presently come to predominantly occupy the risk communication field.

However, it is cautioned that this article is not an attempt to explain the full range of risk related communicative behaviour, nor could it feasibly do so. Rather four approaches to risk communication are distinguished, namely the risk message model, the risk dialogue model, the risk field model and the risk government model. These models should not be considered as providing a definitive account of risk communication, nor should it be considered that any of these models is wholly inaccurate or mistaken. It is also unfortunately beyond the scope of this article to outline the methodological considerations that would accompany each model. Instead the aim is to articulate the particular projection that each way of thinking about risk communication conveys and that their differences should be taken seriously in academic and policy discourse because different conceptions of risk communication bear heavily on its practice. A more fine grained view of risk communication should in the very least generate discussion about which model is most applicable in different contexts and why, on what occasions they may overlap, or in choosing or adhering to a particular model what other considerations might otherwise become hidden or masked from view in risk communication research and practice. 


\section{References}

Alaszewski, A. \& Horlick-Jones, T. (2002) Risk and Health Review of Current Research and Identification of Areas for Further Research, Centre for Health and Social Sciences, University of Kent at Canterbury and School of Social Sciences at Cardiff University.

Austin, J. L. (1962). How to Do Things With Words. Oxford University Press: Oxford, England. Bakir, V. (2005). Greenpeace v. Shell: media exploitation and the Social Amplification of Risk Framework (SARF). Journal of Risk Research. 8, (7-8), 679 - 691

Beck, U. (1992) Risk Society: Towards a New Modernity. New Delhi: Sage.

Boholm, A. (2008) The public meeting as a theatre of dissent. Risk and hazard in land use and environmental planning. Journal of Risk Research, 11 (1-2), 119-140

Bostrom, A. (2003). "Future Risk Communication." Futures, 35 (6), 553-573

Bostrom, A. \& Löfstedt, R.E. (2003). Communicating Risk: Wireless and Hardwired, Risk Analysis, 23(2), 241-248.

Bourdieu, P. (1977). Outline of a theory of practice, Cambridge: Cambridge University Press. Bourdieu, P. (1986). The forms of capital. In J. G. Richardson (ed.), Handbook of Theory and Research for the Sociology of Education. New York: Greewood Press, pp. 241-258.

Breakwell, G. (2001) Mental models and social representations of hazards: The significance of identity processes. Journal of Risk Research, 4 (4), 341-351

Burkart, R. (2007) "On Jürgen Habermas and Public Relations.” Public Relations Review 33(3), 249-54.

Campbell, S. \& Townsend, E. (2003). Flaws undermine results of UK biotech debate. Nature, $425,559$.

Chess, C. (2001) Organizational Theory and the Stages of Risk Communication,

Risk Analysis 21 (1) , 179-188

Coglianese, C. (1997). Assessing consensus: The promise and performance of negotiated rule making. Duke Law Journal, 46, 1255-1333.

Covello, V. T, von Winterfeldt, D. \& Slovic, P. (1986) Risk Communication: A Review of the Literature. Risk Abstracts, 3 (4), 171-182.

Cvetkovich, G. \& Lofstedt, R. (Eds.) (1999). Social trust and the management of risk. London: Earthscan.

Dean, M. (1999). Governmentality: Power and Rule in Modern Society. London: Sage.

Edwards, D. (2005). Discursive Psychology in K. L. Fitch \& R. E. Sanders (Eds.), Handbook of Language and Social Interaction, pp. 257-273. Mahwah, NJ: Lawrence Erlbaum.

European Food Safety Authority (2006). EFSA Risk Communication Strategy and Plans.

European Food Safety Authority

Fiorino, D. J. (1989). Technical and Democratic Values in Risk Analysis. Risk Analysis 9(3), 293299.

Fiorino, D. J. (1990) Citizen Participation and Environmental Risk: A Survey of Institutional Mechanisms. Science, Technology \& Human Values. 15 (2), 226-243.

Fischhoff, B. (1990). Psychology and public policy: Tool or tool maker? American Psychologist, 45, 57-63

Fischhoff, B. (1995) Risk Perception and Communication Unplugged: Twenty Years of Process, Risk Analysis. 15 (2), 137-145.

Fischhoff, B. (2005a). Decision research strategies. Health Psychology, 21(4), S9-16.

Fischhoff, B. (2005b). Risk perception and communication. In D. Kamien (ed.), McGraw-Hill 
Handbook of Terrorism and Counter-terrorism (p. 463-492). New York: McGraw-Hill. Flyvbjerg, B. \& Richardson, T. (2002) "Planning and Foucault: In Search of the Dark Side of Planning Theory." In Philip Allmendinger and Mark Tewdwr-Jones, eds., Planning Futures: New Directions for Planning Theory. London and New York: Routledge, 2002, pp. 44-62. Foucault, Michel (1991) 'Governmentality', in Graham Burchell, Colin Gordon \& Peter Miller (eds.) The Foucault Effect: Studies in Governmentality, Hemel Hempstead: Harvester Wheatsheaf. pp. 87-104

Funtowicz, S. O., \& J. R. Ravetz 1992. Three types of risk assessment and the emergence of postnormal science. In Krimsky, S., and D. Golding, ed. Social theories of risk. p. 251-274. Westport, CT: Praeger.

Giddens, A. (1999). Risk and Responsibility. The Modern Law Review. 62 (1), 1-10

Gouldson, A., Lidskog, R. \& Wester-Herber, M. (2007). The battle for hearts and minds?

Evolutions in corporate approaches to environmental risk communication. Environment and

Planning C: Government and Policy, 25, 56-72

Grice, H. P. (1957). Meaning. Philosophical Review, 64, 377-388.

Grice, H. P. (1969). Utterer's meaning and intentions. Philosophical Review, 78, 147-177.

Gurabardhi, Z., Gutteling, J. and Kuttschreuter, M. (2005) An empirical analysis of

communication flow, strategy, and stakeholders' participation in the risk communication literature 1988-2000, Journal of Risk Research. 8 (6), 499-511.

Gurabardhi, Z., Gutteling, J. M., \& Kuttschreuter, M. (2004). The Development of Risk

Communication: An Empirical Analysis of the Literature in the Field, Science Communication, 25 (4), 323-349

Habermas, J. (1984). The theory of communicative action. Volume 1. Reason and the rationalization of society. Boston, MA: Beacon Press.

Habermas, J. (1987). The theory of communicative action. Volume 2. Lifeworld and system: A critique of functionalist reason. Boston, MA: Beacon Press.

Hall, S. (1980). "Encoding/decoding". In Culture, Media, Language: Working Papers in Cultural Studies, 1972-1979. London: Hutchinson.

Holmstrom, S. (2005) Reframing public relations: The evolution of a reflective paradigm for organizational legitimization, Public Relations Review 31, 497-504

Hood, C., Rothstein, H. and Baldwin, R. (2001). The Government of Risk: Understanding risk regulation regimes, Oxford: Oxford University Press.

Hood, C. \& Heald, D. (2006). Transparency: The Key to Better Governance, Oxford, British Academy/OUP

Horlick-Jones, T. (2008) Communities of Risk Research and Risk Practice: Divided by a Common Language? Journal of Risk Research, 11(1-2), 169-174

Horlick-Jones, T. \& Sime, J. (2004). Living on the border: knowledge, risk and transdisciplinarity, Futures 36 (4), 441-457

ISO (2002), Risk Management - Vocabulary - Guidelines for Use in Standards, ISO/IEC Guide 73: 2002, Geneva: International Organization for Standardization.

Jaeger, C.J., Renn, O., Rosa, E.A. and Webler, T. (2001). Risk, Uncertainty, and Rational Action, Earthscan, London

Jasanoff, S. (1989) "Differences in National Approachcs to Risk Asscssment and Management," given at a Symposium on "Managing the Problem of Industrial Hazards: The International Policy Issucs" (National Academy of Sciences, Washington, D.C. February 27, 1989). Cited in Morgan G, Lave L. 1990. Ethical considerations in risk communication practice and research. Risk 
Analysis 10, 355-358

Joffe,H. (2003). Risk: from perception to social representation. British Journal of Social Psychology 42(1), 55-73.

Jovchelovitch, S. (2007) Knowledge in context: representations, community and culture. London: Routledge.

Kasperson, R. E., Renn, O., Slovic, P., Brown, H. S., Emel, J., Goble, R., Kasperson, J. X., \& Ratick, S. (1988) The Social Amplification of Risk: A Conceptual Framework. Risk Analysis 8 (2), 177-187

Kelly, P. (2001) 'Youth at Risk: Processes of Responsibilization and Individualization in the Risk Society', Discourse, 22 (1), 23 -34.

Kelly, P. (2003) Growing Up as Risky Business? Risks, Surveillance and the Institutionalised Mistrust of Youth, Journal of Youth Studies, 6, 2, 165-180.

Klinke, A. \& Renn, O. (2002). A new approach to risk evaluation and management: Risk-based, precaution-based and discourse-based strategies. Risk Analysis, 22(6), 1071-1094

Krauss, R. M. \& Fussell, S. R. (1996). Social psychological models of interpersonal communication. In E. T. Higgins \& A. Kruglanski (Eds.), Social psychology: Handbook of basic principles (pp. 655-701). NY: Guilford Press.

Krauss, R. M. \& Morsella, E. (2000) Communication and Conflict. In M. Deutsch \& P. Coleman, (Eds.), The handbook of constructive conflict resolution: Theory and practice (131-143).

Leiss, W. (1996) Three phases in the evolution of risk communication practice. Annals of the American Academy of Political and Social. Science, 545, 85-94

Lemke, T. (2004). Disposition and determinism - genetic diagnostics in risk society.

Sociological Review, 22(4), 550-566

Löfstedt, R. E. (2005) Risk Management in Post-Trust Societies. Palgrave MacMillan, Basingstoke, Hampshire, UK and New York.

Lofstedt, R. E. \& 6, P. (2008). What environmental and technological risk communication research and health risk research can learn from each other. Journal of Risk Research, 11(12), $141-167$

Lofstedt, R.E., Renn, O. (1997). The Brent Spar controversy: an example of risk communication gone wrong, Risk Analysis, 17(2), 131-36

Luhmann, N. (1995). Social systems. Stanford, CA: Stanford University Press.

McComas, K. A. (2006). Defining moments in risk communication research: 1996-2005. Journal of Health Communication, 11(1), 75-91

Morgan G, Lave L. 1990. Ethical considerations in risk communication practice and research.

Risk Analysis 10,355-358

Morgan, M.G., Fischhoff, B., Bostrom, A. \& Atman, C.J. (2001) Risk Communication: A Mental Models Approach. Cambridge University Press.

Murdock, G., Petts, J. \& Horlick-Jones, T. (2003): After amplification: rethinking the role of the media in risk communication. In: Pidgeon, N., Kasperson, R. E. \& Slovic, P (eds.): The Social Amplification of Risk. Cambridge University Press, 156-178.

National Research Council (1989). Improving Risk Communication. National Academy Press, Washington D.C.

Nelkin, D. (2002). Communicating Risk: Once Again, Political Communication, 19(4), 461 - 463

O'Neill, O. (2002). A Question of Trust: The BBC Reith Lectures 2002. Cambridge, UK:

Cambridge University Press

OECD (2002) Guidance Document on Risk Communication for Chemical Risk Management, 
Series on Risk Management, Environment, Health and Safety Publications, Paris: Organization for Economic Co-operation and Development.

Palenchar, M. J., \& Heath, R. L. (2007). Strategic risk communication: Adding value to society. Public Relations Review, 33, 120-129.

Pellizzoni, L. (2001). The Myth of the Best Argument: power deliberation and reason', British Journal of Sociology, 52 (1), 59-86.

Petts, J. (2001). Evaluating the effectiveness of deliberative processes: waste management case studies. Journal of Environmental Planning \& Management, 44(2), 207-226

Pidgeon, N.F. (1998). Risk assessment, risk values and the social science programme: why we do need risk perception research, Reliability Engineering and System Safety, 59, 5-15.

Pidgeon, N.F., Kasperson, R.K. and Slovic, P. (2003) The Social Amplification of Risk.

Cambridge, CUP.

Pidgeon, N. F., Poortinga, W., Rowe, G., Horlick-Jones, T., Walls, J. \& O'Riordan T (2005)

Using Surveys in Public Participation Processes for Risk Decision Making: The Case of the 2003 British GM Nation? Public Debate, Risk Analysis 25 (2), 467-479

Pidgeon, N. F. \& Rogers-Hayden, T. (2007). Opening up Nanotechnology Dialogue with the Publics: Risk Communication or 'Upstream Engagement'. Health Risk and Society 9, 191-210. Powell, D.A. (2000). Food safety and the consumer - perils of poor risk communication. Canadian Journal of Animal Science, 80(3), 393-404

Power, M. (2004). The Risk Management of Everything: Rethinking the politics of uncertainty. London: Demos.

Rayner S. (1988) Muddling Through Metaphors to Maturity: A Commentary on Kasperson et al., The Social Amplification of Risk. Risk Analysis 8 (2), 201-204

Rayner, S. \& Cantor, R., (1987) 'How fair is safe enough? The cultural approach to technology choice', Risk Analysis: An International Journal, 7(1), 3-9.

Renn, O. (1998). Three decades of risk research: accomplishments and new challenges, Journal of. Risk Research 1(1), 49-71

Renn, O. (2006): Risk Communication Consumers between Information and Irritation. Journal of Risk Research, 9(8), 833-850

Ropeik, D., \& Slovic, P. (2006). Risk Communication: A neglected tool in protecting public health. Eurohealth, 12(3), 40-42.

Rosa, E. A. (1998) Metatheoretical Foundations for Post-Normal Risk." Journal of Risk Research, $1,15-44$.

Rose, N. (1999) Powers of Freedom: Reframing Political Thought. Cambridge University Press Rose, N. and Miller, P. (1992) 'Political Power Beyond the State: Problematics of Government', British Journal of Sociology 43(2), 173-205

Rossi, J. (1997). Participation run amok: The costs of mass participation for deliberative agency decisionmaking. Northwestern University Law Review , 92, 173-249.

Rothstein, H., Huber, M., and Gaskell, G. (2006). A Theory of Risk Colonisation: The spiralling regulatory logics of societal and institutional risk. Economy and Society, 35 (1), 91-112.

Rowe, G. and Frewer, L. (2000) Public participation methods: A framework for evaluation, Science, Technology and Human Values, 25 (1), 3-29.

Schedler, Petra E., Folke F. Glastra and Erik Katz (1998). "Public Information and Field Theory. Political Communication 15, 445-461.

Schlag, A. K. (2007) Expert and Lay Representations of GM Food: Implications for Risk Communication. Unpublished PhD Thesis. London School of Economics: University of London. 
Schinkel, W. (2007). Sociological discourse of the relational: the cases of Bourdieu \& Latour. The Sociological Review, 55(4), 707-729.

Slovic, P. (1993). Perceived risk, trust, and democracy. Risk Analysis, 13, 675-682.

Smith, C. (2000). The sovereign state v Foucault: Law and disciplinary power. Sociological Review 48(2), 283-306

Stern, P. C. and Fineberg, H. C. (1996) Understanding Risk: Informing Decisions in a Democratic Society, Washington, DC: US National Research Council.

Stirling, A. (2005) Opening up or closing down? Analysis, participation and power in the social appraisal of technology. In M. Leach, I. Scoones, and B. Wynne (eds.) Science and Citizens: Globalisation and the Challenge of Engagement (London: Zed Books), pp. 218 - 231.

Sturgis, P. J., \& Allum, N. (2004). Science in society: re-evaluating the deficit model of public attitudes. Public Understanding of Science, 13(1), 55-75

Sunstein, C. R. and Thaler, R. H. (2003). "Libertarian Paternalism is Not an Oxymoron." University of Chicago Law Review 70(4), 1159-1202.

Taylor-Gooby, P. \& Zinn, J. O. (2006) Current Directions in Risk Research: New Developments in Psychology and Sociology. Risk Analysis, 26 (2), 397-411

UK Government Cabinet Office Strategy Unit (2002) Risk: Improving government's capability to handle risk and uncertainty. London: Cabinet Office.

US Government National Research Council (1989) Improving Risk Communication, National

Academy Press

Walls, J., Pidgeon, N., Weyman, A. \& Horlick Jones, T. (2004). Critical trust: Understanding lay perceptions of health and safety regulation. Health, Risk and Society, 6(2), 133-150.

Wardman, J.K. (2006). Toward a Critical Discourse on Affect and Risk Perception. Journal of Risk Research, 9 (2), 109-124.

World Health Organisation (2002). Establishing a dialogue on risks from electromagnetic fields, Geneva: World Health Organisation.

Wynne, B. (1989). Sheep farming after Chernobyl, a case study in communicating scientific information. Environment, 31(2), 10-15

Wynne, B. (1992) Risk and Social Learning: Reification to Engagement, in S. Krimsky and D. Golding (eds) Social Theories of Risk pp. 275-97, Westport, CT: Praeger.

[1] The notion of normative, instrumental and substantive imperatives was first characterised by Fiorino (1990) to account for different arguments for engaging in dialogue on risk. Authors previously citing these three arguments have tended to place emphasis on the normative - as distinct from $a$ normative - rationale for dialogue at each stage in risk management and appraisal following the earlier concerns of Fiorino's (1990) work (see also Stern and Fineberg 1996 for example). The conceptualisation and development of these imperatives notably tends to vary slightly between authors however, readers may therefore wish to consult the citations listed above for alternative interpretations.

[2] The encoder/decoder communication paradigm as it is conceived and articulated here follows a social psychological approach offered by Kraus and Fussel (1996). This approach differs somewhat in interpretation to that provided by authors such as Schedler et al. (1998) following the work of Hall (1980), which takes a more contextualised view of the encoding/decoding process. Instead, this view of encoding/decoding is perhaps more similarly in conception to the simpler 'transmission model' outlined by Schedler et al. (1998).

[3] The mental models approach (Morgan et al. 2002) is primarily a methodological approach to 
risk communication design rather than a way of conceptualising risk communication per se though the authors of this approach have in part elaborated upon its conceptual foundations. The mental models approach is understood to be generally rooted in the psychology of risk perception and so is primarily individualistic in focus. However, the approach recognises that understanding, knowledge and experience between communication participants is not necessarily isomorphic and needs to be appreciated in communication design. More recently researchers such as Breakwell (2001) and Schlag (2007) have also begun to extend the social dimensions of the mental models approach in light of Moscovici's Social Representations Theory, and in so doing have highlighted how the approach may take into account such factors as the differences in knowledge and belief systems between people from different subcultures.

[4] This idea is particularly informed by a reading of Lemke's (2004) argument on the social power of genetic information which places emphasis on analysing 'technologies of power' rather than the 'power of technologies' and their role in defining the particular subjectivities of individuals.

\author{
Normative \\ Instrumental \\ Substantively Engaged \\ Risk Field Model \\ Risk Government Model \\ Risk Dialogue Model \\ Risk Message Model
}

Substantively Disengaged 